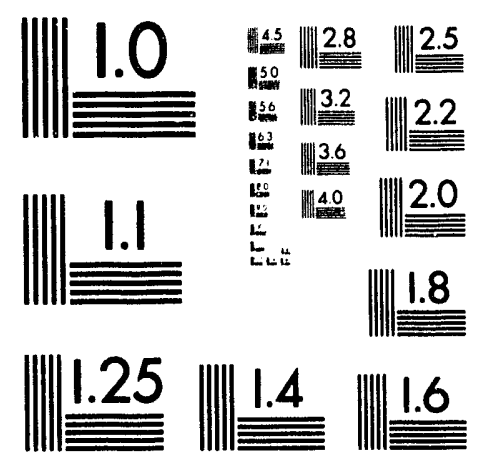



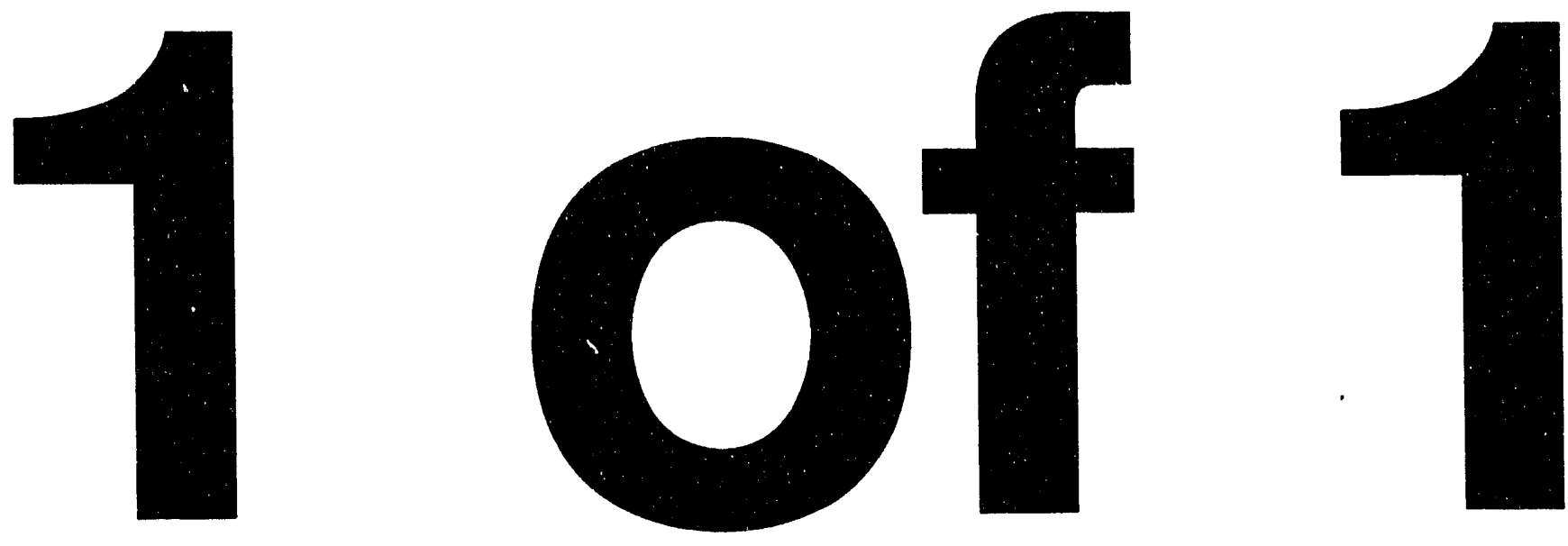
Conf $-921.256-7$

UCRL-JC-111666

PREPRINT

\title{
CUTTING AND DRILLING STUDIES USING HIGH POWER VISIBLE LASERS
}

\author{
D.D. Kautz \\ E.P. Dragon \\ M.E. Werve \\ R.S. Hargrove \\ B.E. Warner
}

This paper was prepared for submittal to the

International Conference on Lasers '92

Houston, TX

December 8, 1992

May 27, 1993

This is a preprint of a paper intended for publication in a joumalor proceedinge Since changes may be made before publication, this preprint is made available with the underatanding that it will not be cited or reproduced without the permission of the author.

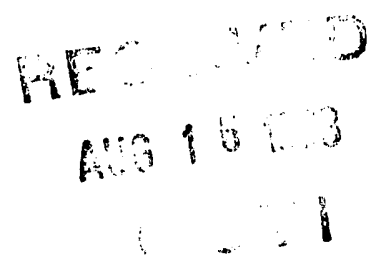


This document was prepared as an account of work sponsored by an agency of the United States Goverhment. Neither the United States Government nor the University of California nor any of their employees, makes any warranty, express or implied, or assumes any legal liability or responsibility for the sccuracy, completeness, or usefulness of any information, apparat us, product, or process disces id, or represents that its use would not infringe privately owned rights. Reference her ein to any specific commercial products, process, or service by trade name, trademark, manuf acturer, or otherwise, does not necessarily constitute or imply its endorsement, recommendation, or favoring by the United States Government or the University of California. The views and opinions of authors expressed herein do not necessarily state or reflect those of the United States Government or the University of Califomia, and shall not be used for advertising or product endorsement purposes. 


\title{
CUTTING AND DRILLING STUDIES USING HIGH POWER VISIBLE LASERS
}

\author{
D. D. Kautz \\ E. P. Dragon \\ M. E. Werve \\ R. S. Hargrove \\ B. E. Warner \\ University of California \\ Lawrence Livermore National Laboratory \\ P. O. Box 808, L-350 \\ Livermore, CA 94551
}

\begin{abstract}
High power and radiance laser technologies developed at Lawrence Livermore National Laboratory such as coppervapor and dye lasers show great promise for material processing tasks. Evaluation of models suggests significant increases in welding, cutting, and drilling capabilities, as well as applications in emerging technologies such as micromachining, surface treatment, and stereolithography. Copper and dye laser systems are currently being developed at LLNL for uranium enrichment production facilities. Copper lasers currently operate at $1.8 \mathrm{~kW}$ output at approximately three times the diffraction limit and achieve mean time between failures of more than 1000 hours. Dye lasers have near diffraction limited beam quality at greater than $1.0 \mathrm{~kW}$. Results from cutting and drilling studies in titanium and stainless steel alloys show that cuts and holes with extremely fine features can be made with dye and copper-vapor lasers. High radiance beams produce low distortion and small heat-affected zones. We have accomplished very high aspect ratios (> 60:1) and features with micron scale (5 - 50 um) sizes.

\section{Introduction}

Use of lasers for cutting and drilling is well established in industry. Conventional $\mathrm{CO}_{2}$ and $\mathrm{Nd}$ :YAG lasers have become workhorses for these activities. At Lawrence Livermore National Laboratory (LLNL), researchers have developed several new high power and radiance lasers allowing the processing window for laser material processing to be widened due to improved beam/material interaction properties. This paper will discuss and compare laser material processing using copper vapor laser-pumped dye and copper vapor lasers.
\end{abstract}

\section{Description of Equipment}

\section{Material Processing Laser System}

A Laserdyne 520, 3-axis CNC machine workstation was attached to our dye and copper vapor laser beamlines. Both beams travel several hundred feet through a conventional optical train to reach this workstation. Technicians placed a standard laser cut box with an aluminum honeycomb top on the machine table to allow specimens to be held in place with a slight negative pressure.

\section{Laser Diagnostic Systems}

We developed two sets of diagnostic tools for material processing studies, a beam measurement system and a penetration detector. These tools were important instruments for making accurate measurements during material processing studies.

Beam Measurement System. Figure 1 shows a schematic of the beam measurement system used on copper vapor and dye laser beams. This system allows low power beam spot size measurements on a very fine scale. The z-axis of the CNC machine is moved to find the smallest (focal) spot size. This measurement system also allows several measurements to be made outside the focal spot. This data is useful in determining the depth of focus of the lens used and the beam size at various locations of defocus. This data is especially valuable when processing thick sections to determine the proper placement of the focal spot to produce small tapers in holes and kerfs. 
Beam Penetration Detector. Figure 2 shows a schematic of the beam penetration detector. This detector allows the measurement of drilling time through a workpiece. Two photodiodes are placed in a circuit with the oscilloscope software in a computer data acquisition system. The photodiode above the workpiece switches on and triggers the oscilloscope when it senses reflected light from the workpiece. The oscilloscope measures the length of time until the workpiece has been fully penetrated. At this point, the light gathered by the photodiode under the workpiece also switches on. The voltage measured by the second photodiode is then subtracted from the voltage measured by the first photodiode. This allows the user to determine the amount of light making it through the hole in the workpiece. Typically, there is a slight ramping before the voltage of the second photodiode becomes steady. This is because the hole does not pass as much light through at first breakthrough as when the hole size has reached a steady size.

\section{Cutting Theory}

High brightness lasers provide significant improvement of laser properties important to increasing the productivity achieved with industrial lasers. Short wavelength and improved beam quality lead to smaller beam spot size, while the pulsed beam format decreases the peak temperatures reached in the material. These combined, make fabrication of smaller features feasible and decrease the volume of heat affected material remaining in the fabricated part after laser processing.

Work by Swift-Hook and Gick and others 1,2 illustrates this to be true for high energy density beams. Figure 3 shows the dependence of material cutting and drilling properties on the normalized speed and power using Swift-Hook and Gick's analysis. The normalized speed function is

$$
V_{N}=v w / D
$$

where

$\mathbf{v}$ is workpiece velocity,

$w$ is beam spot size, and

$D$ is the material thermal diffusivity.

The normalized power function is

$$
\mathbf{P}_{\mathrm{N}}=\mathbf{n} \mathrm{P}_{\mathrm{o}} / \mathrm{aS}
$$

where

$\mathbf{n}$ is the laser coupling efficiency,

$P_{0}$ is the laser power,

$a$ is the material thickness, and

$\mathrm{S}$ is the material heat function.

The lower portion of the curve shows the conduction melting mode typically used for welding, while the upper portion is the keyhole mode used for high aspect ratio material processing operations. Datapoints that fall on the conduction mode portion of the curve are typical of that fitting a Rosenthal heat flow model using a point source. Datapoints that fall on the keyhole mode portion of the curve are typical of Rosenthal's model when using a line source 3. The transition between is not well documented in the literature, but welds made in this regime show characteristics of both conduction and keyhole mode heat flow.

\section{Experimental Results}

We ran several cutting and drilling studies on both Ti-6Al-4V and AISI 304t stainless steel using both copper vapor and dye lasers. These studies to date have used a wide range of thicknesses and power levels on the dye laser. Cupper vapor laser material processing studies have been confined to very low powers and thin section sheet material while we have been testing the beamline for robustness at this wavelength of light.

\section{Results of Cutting Studies}

In materials of thin, but not foil, thicknesses, the dye laser has typically produced cuts with kerfs ranging between 10 to 50 micrometers in width. The copper vapor laser produces kerfs in the same materials that range from 20 to 50 micrometers in width. Plots of some dye laser data and their correlation with the curve generated by Swift-Hook and Gick are shown as the datapoints in Figure 3. 
The major difference noted at this point between the dye and the copper vapor laser cuts has been the quality of the kerf. The dye laser generated kerfs have exhibited rough surfaces with a large amount of vapor and liquid droplet redeposition on the surface. The copper vapor laser generated kerfs have been smooth similar to those found when using $\mathrm{Nd}$ :YAG and $\mathrm{CO}_{2}$ lasers.

Microstructurally, the heat-affected zones associated with cuts made using dye and copper vapor lasers are very small. Figure 4 shows the lack of a heat-affected zone in a cut made through AISI 304 stainless steel.

\section{Results of Drilling Studies}

The studies done on drilling have shown two regimes: A linear region where thickness penetrated is a strong function of the time and power needed to produce holes and an equilibrium condition where material removal is approximately balanced by material redeposition. Holes made in Ti-6Al-4V and AISI 304 stainless steel alloys have both exhibited this phenomena and other studies have also found the equilibrium condition to occur when drilling with other types of lasers ${ }^{4}$. Figure 5 shows data generated using a dye laser in both regimes.

Microstructurally, the heat-affected zones associated with holes made using dye and copper vapor lasers are very small. The edge quality is also very good with minimal taper exhibited in holes, although through use of defocusing techniques, taper can be added to holes. Figure 6 shows a series of holes made in Ti-6Al-4V alloy.

\section{Summary}

This work shows that new generation lasers with short wavelengths and high beam quality can be used to drill fine holes in engineering materials. The aspect ratios generated in these studies were very high, up to 60:1. This technology opens capabilities for micromachining of parts never before available for commercial applications.

\section{Acknowledgments}

This work was supported under the auspices of the U. S. Department of Energy by Lawrence Livermore National Laboratory under contract W-7405-ENG-48.

\section{References}

Swift-Hook D.T. and A.E.F. Gick "Penetration with lasers", Welding Journal. Vol. 52, No. 11 (1973), pages 492s-499s.

\section{Wang F.F.Y. Materials Processing Theory and Practices. Vol. 3, North-Holland Publishing Company} (1983).

Rosenthal D. "Mathematical theory of heat distribution during welding and cutting", Welding Journal. Vol. 20, No. 5 (1941), pages 220s-234s.

Bransch Harald N. "Cutting and drilling using Nd:YAG lasers with fiber-optic beam delivery", Proceedings from International Conference on Lasers '91. STS Press (1992). 


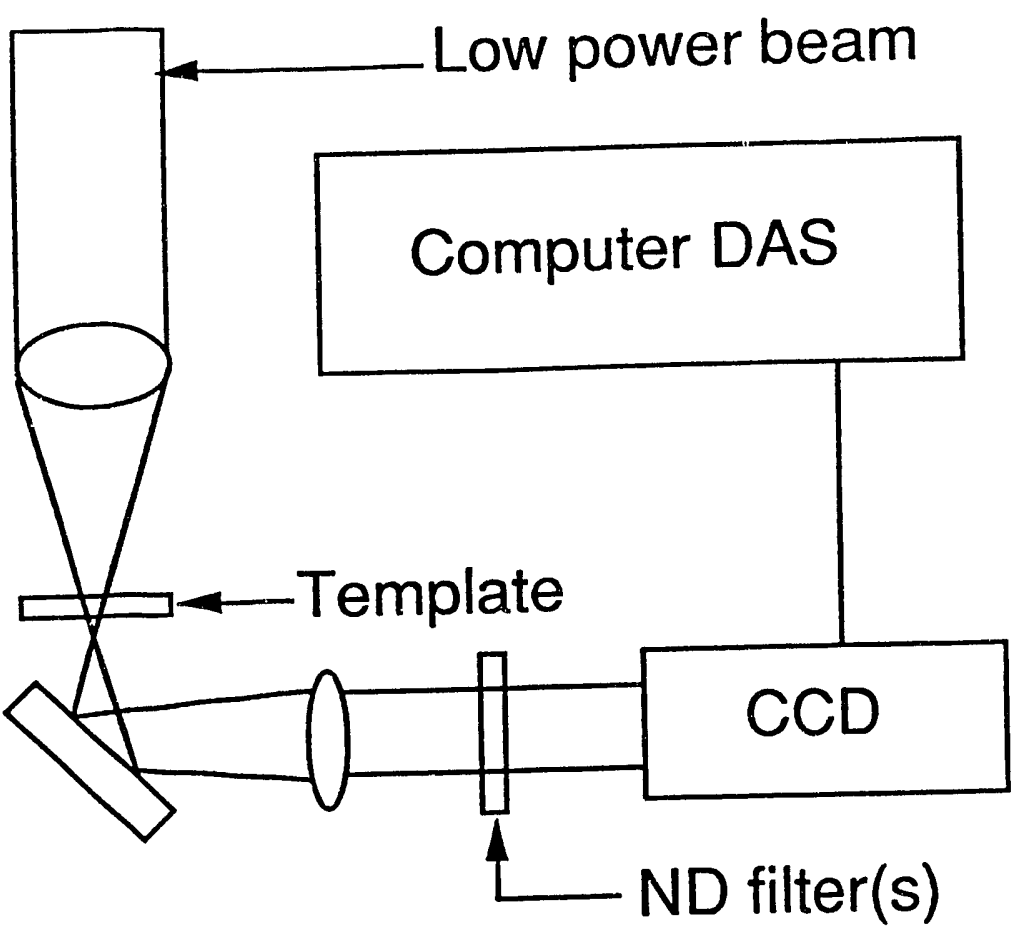

Figure 1. Beam measurement system.

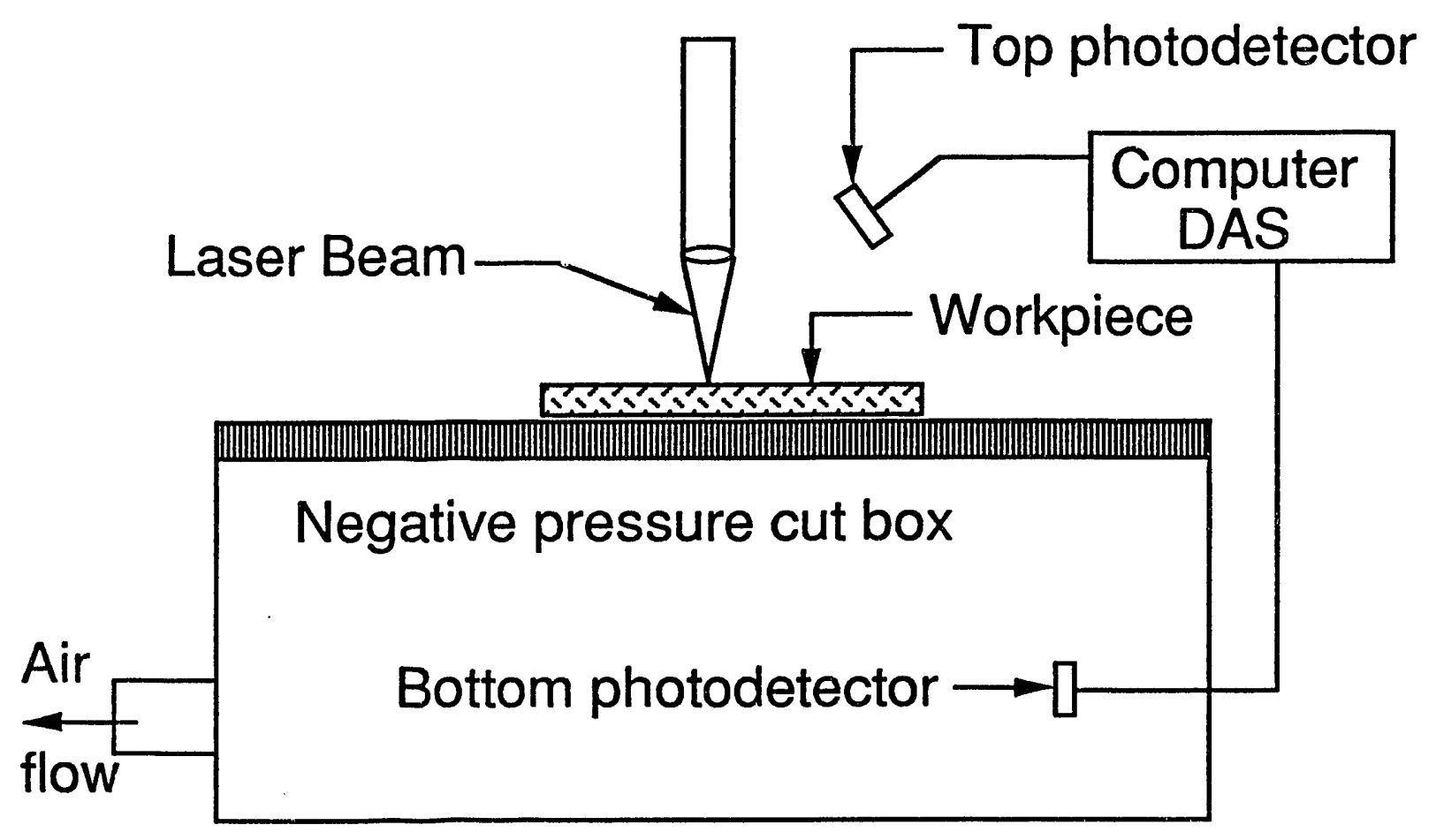

Figure 2. Beam penetration detector system. 


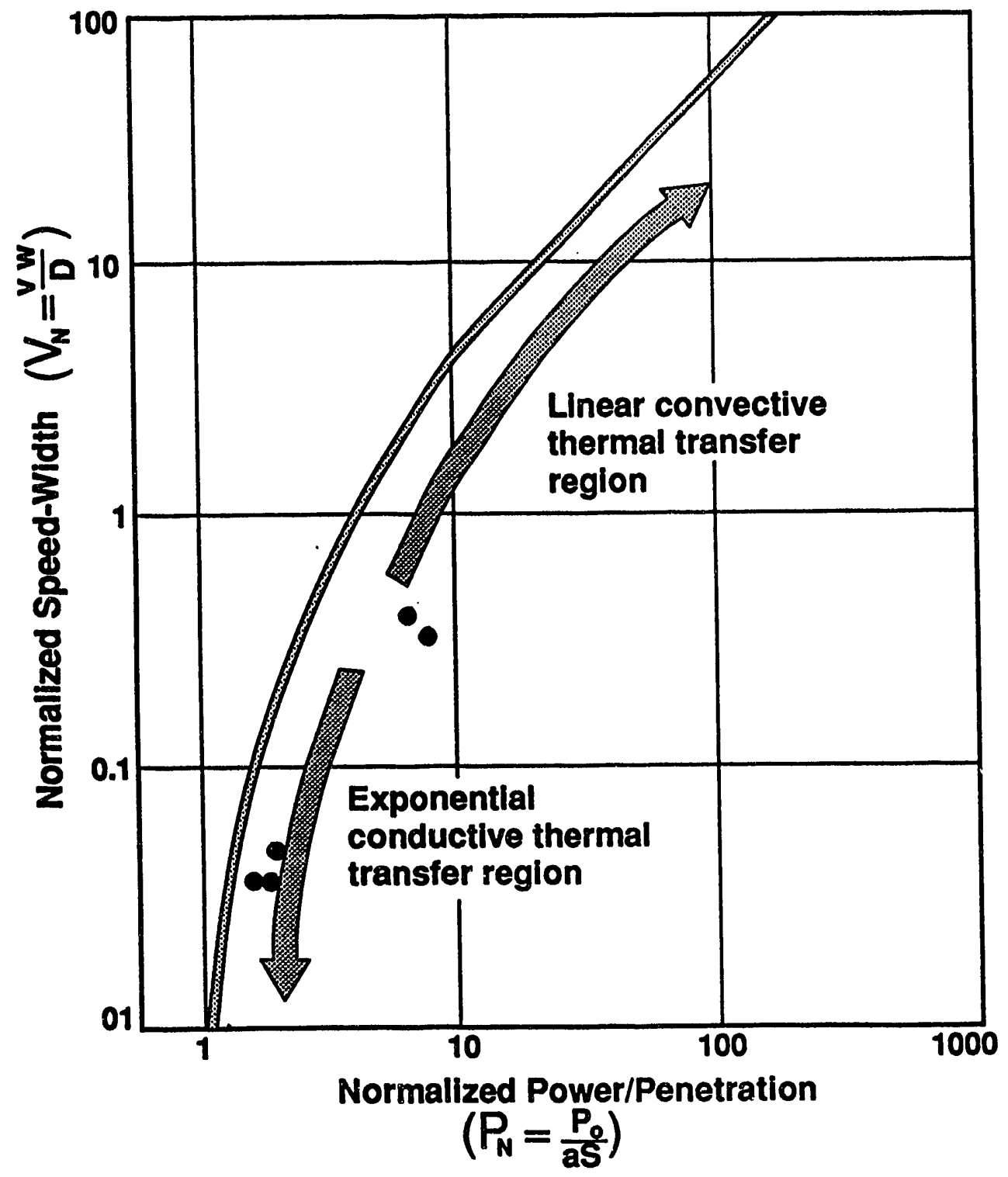

Figure 3. Swift-Hook and Gick analysis of penetration, power and speed. 


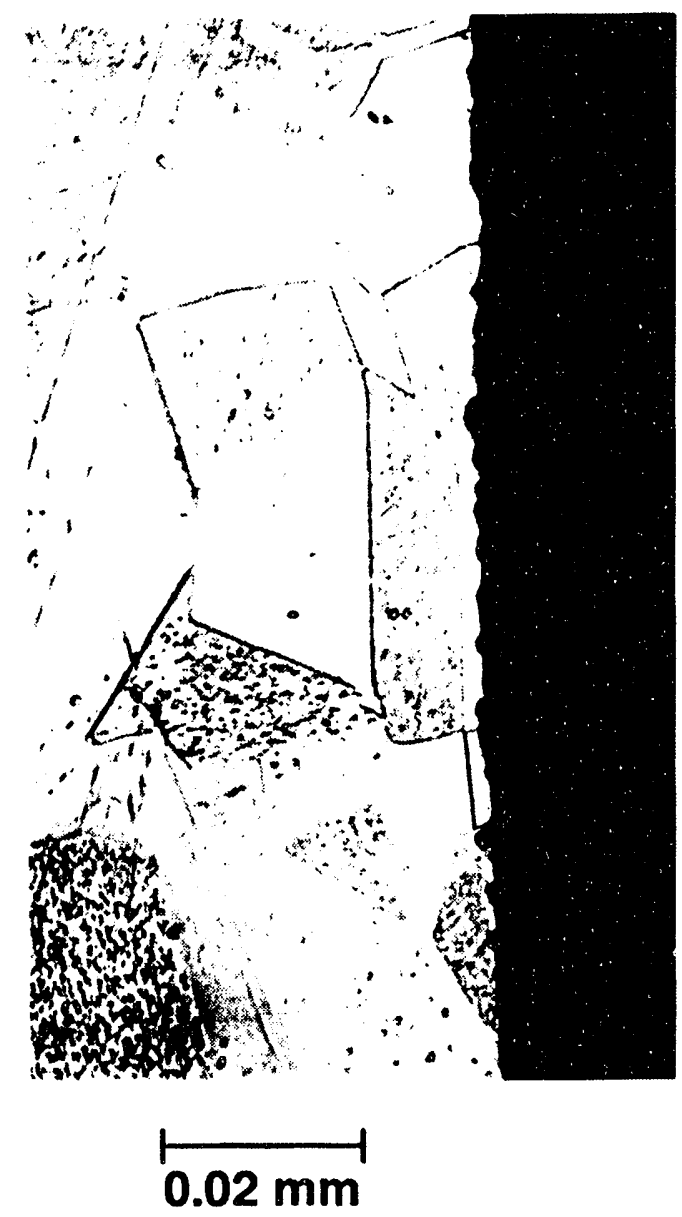

Figure 4. High magnification photomicrograph showing lack of heat-affected zone in dye laser cut. 


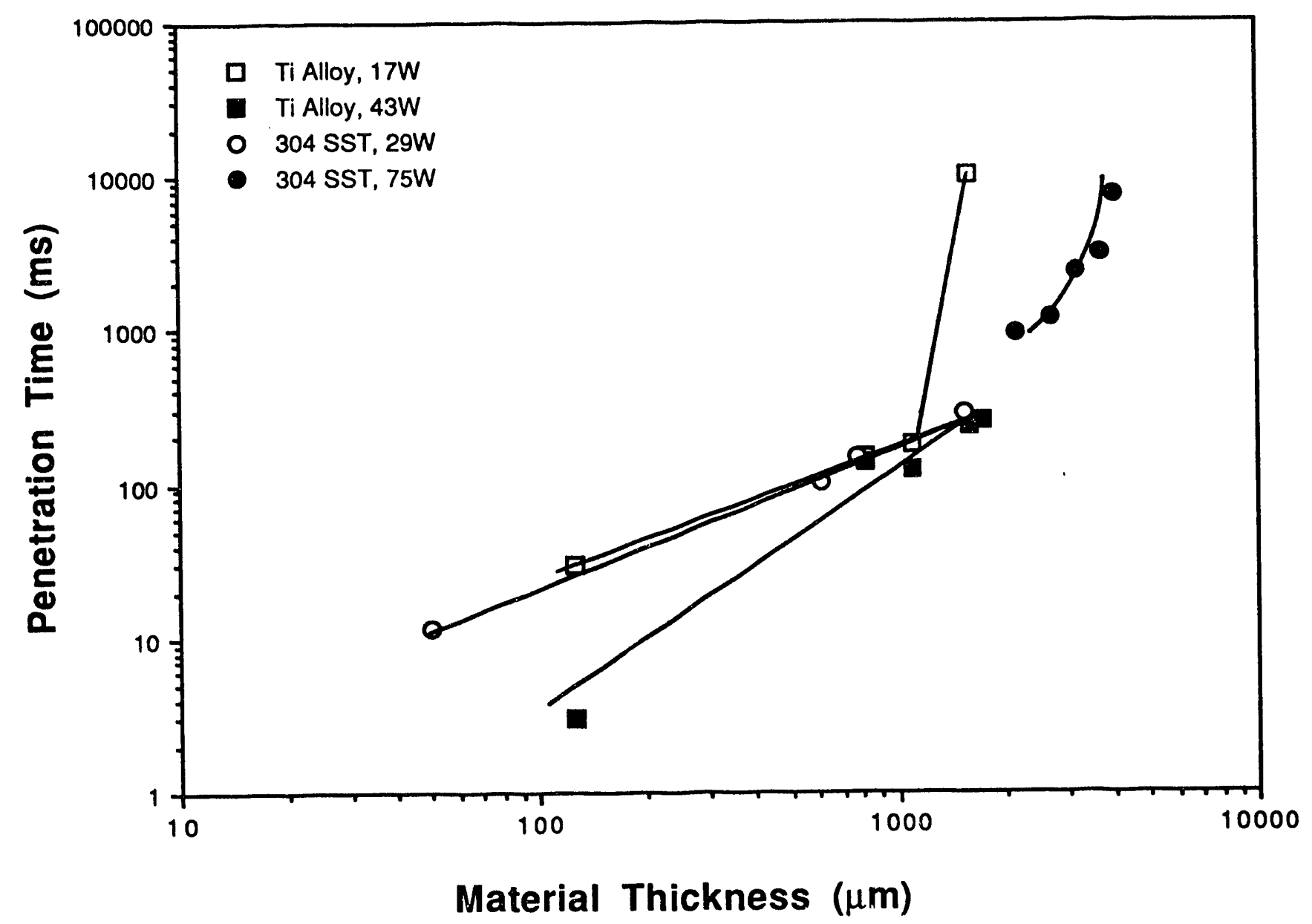

Figure 5. Thickness penetrated as a function of time for dye laser. 


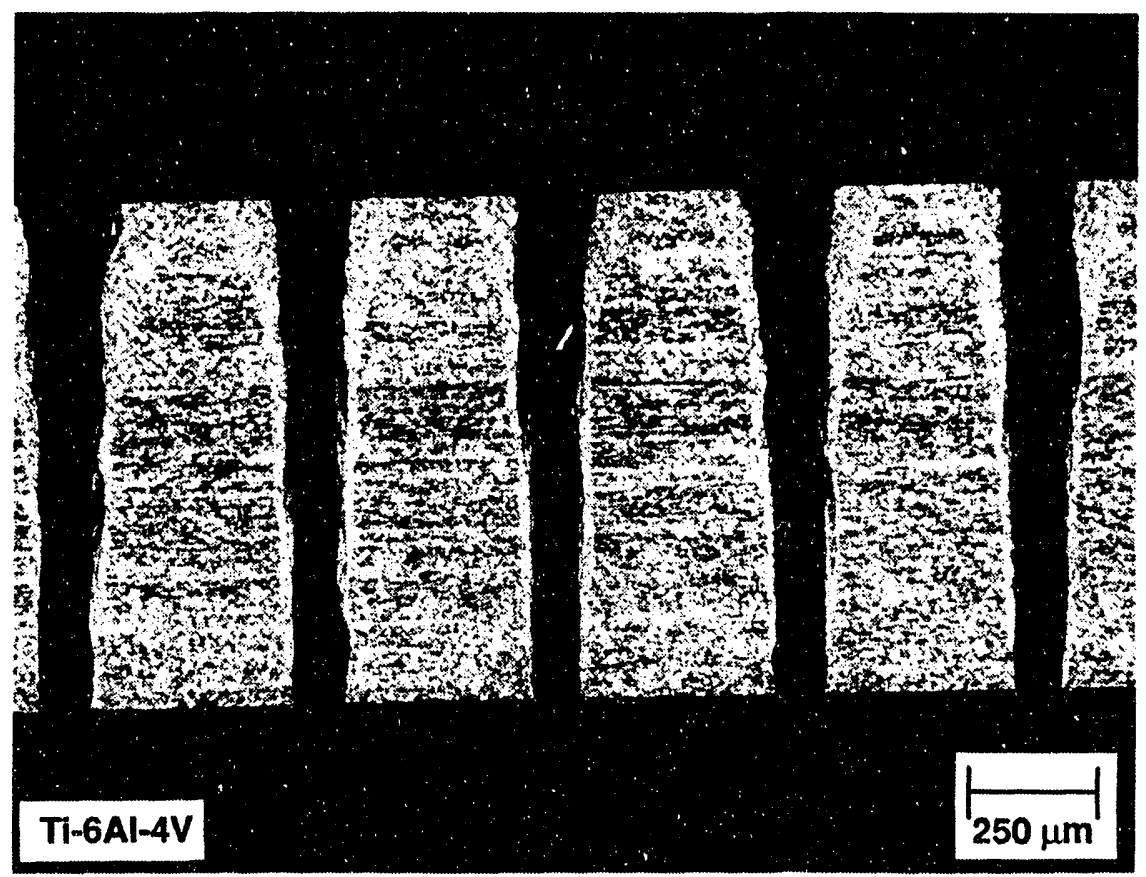

Figure 6. Series of holes drilled in Ti-6Al-4V alloy. 

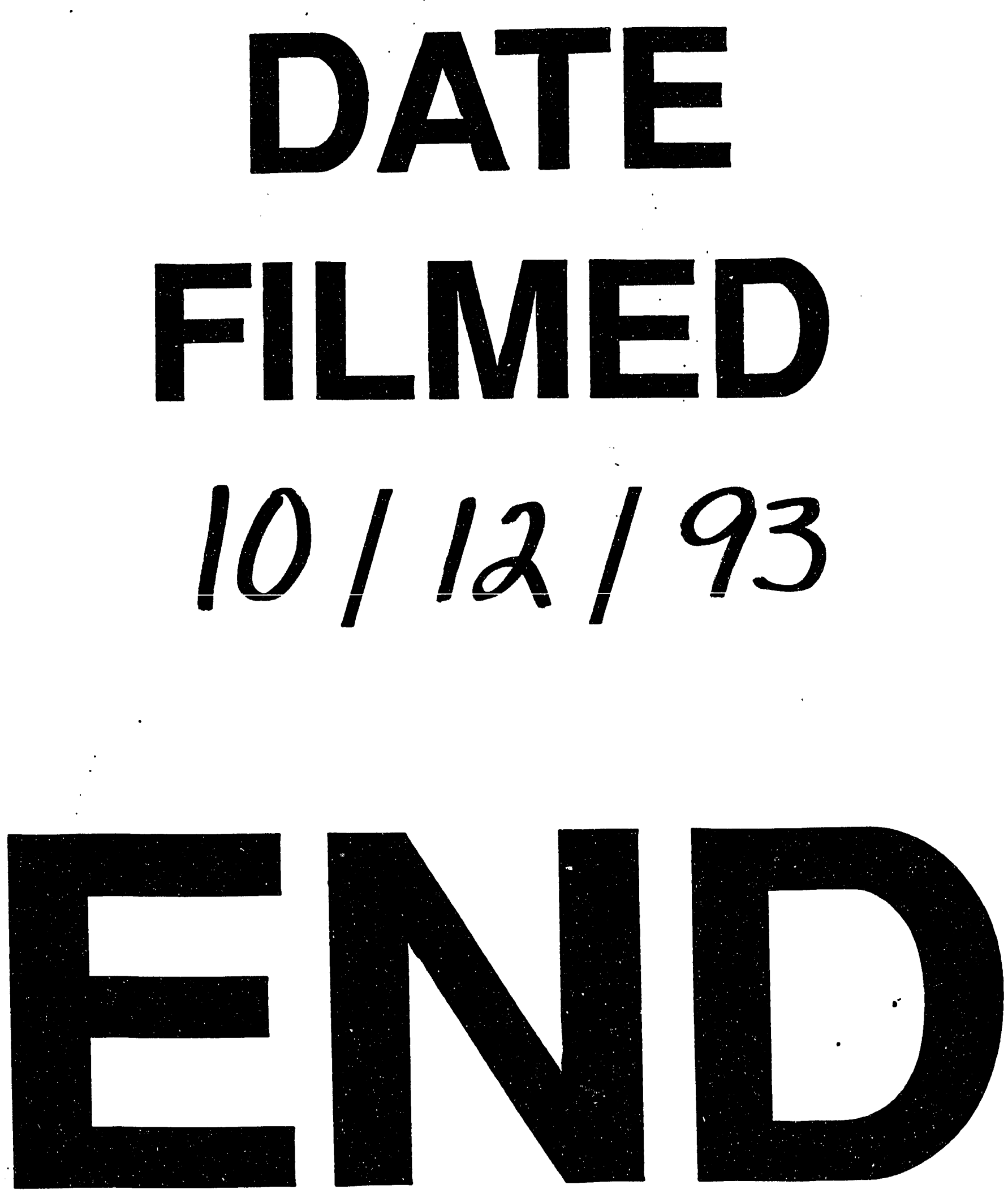